\title{
Safety of Transvaginal Scan Estimated from Ultrasonic Bioeffects
}

\section{Kazuo Maeda}

\section{ABSTRACT}

The embryo and fetus are generally studied using ultrasound imaging in pregnancy; however, ultrasound wave is absorbed by biological tissues to elevate the temperature. The growing embryonic and fetal tissue tends to be damaged by heating; thus, excess heating that damages young sensitive growing tissue should be prevented in ultrasound diagnosis. Hence, the thermal status of diagnostic ultrasound should be known with thermal index $(\mathrm{TI})$, of which the determination and application are discussed in this chapter. Peculiar problem to transvaginal scan and thermal problem in febrile patient are discussed.

Additionally, the cavitation, which is related with negative pressure, develops high pressure, high temperature, and free radicals that damage embryonic and fetal tissues. Therefore, the mechanical index (MI) has to be determined, measuring negative pressure of ultrasound. The $\mathrm{Ml}$ is determined for the safety of diagnostic ultrasound.

The ultrasound device output intensity that suppresses fetal amniotic JTC-3 cultured cell growth was determined, where $240 \mathrm{~mW} / \mathrm{cm}^{2}$ or less output intensity did not suppress the cell growth, namely, the diagnostic ultrasound has no bioeffect when the output is lower than $240 \mathrm{~mW} / \mathrm{cm}^{3}$.

The as low as reasonably achievable principle in the Doppler method of $0.1 \mathrm{TI}$ will be discussed. Three experimental reports of hazardous effects of ultrasound are discussed.

Keywords: Bioeffect, Safety, Mechanical index, Teratogenicity, Thermal index, Transvaginal scan, Ultrasound.

How to cite this article: Maeda K. Safety of Transvaginal Scan Estimated from Ultrasonic Bioeffects. Donald School J Ultrasound Obstet Gynecol 2017;11(1):1-6.

\section{Source of support: Nil}

\section{Conflict of interest: None}

\section{INTRODUCTION}

Although no adverse effect of ultrasound diagnosis has been reported in clinical medicine, ultrasound bioeffects and the safety of diagnostic ultrasound have been frequently discussed by medical ultrasound organizations

\footnotetext{
Honorary Professor

Department of Obstetrics and Gynecology, Tottori University Medical School, Yonago, Japan

Corresponding Author: Kazuo Maeda, Honorary Professor Department of Obstetrics and Gynecology, Tottori University Medical School, Yonago, Japan, Phone: +0081859226856 e-mail:maedak@mocha.ocn.ne.jp
}

including the World Federation of Ultrasound in Medicine and Biology (WFUMB) (Fig. 1). ${ }^{1}$

It was emphasized in the safe use of ultrasound that ultrasound examination is performed only by medical indications, and it should be recognized that young biological tissues of developing embryos and fetuses may be damaged by intense ultrasound, ${ }^{2}$ where the user should be responsible for the ultrasound safety. ${ }^{3}$

The main biological effect is the thermal effect due to temperature rise induced by ultrasound absorption, because of the teratogenicity of high temperature. ${ }^{4}$ Nonthermal effects are inertial cavitation and other mechanical effects. No thermal effect is expected in common B-mode imaging device because of minimal heat production due to low ultrasound intensity, i.e., WFUMB concluded that the use of simple imaging equipment is not contraindicated on thermal grounds. ${ }^{1}$ Simple transvaginal B-mode, three-dimensional (3D) and four-dimensional (4D) imaging are included in this category. The International Society of Ultrasound in Obstetrics and Gynecology (ISUOG) also stated the safe use of Doppler ultrasound. More practical plans on the safe use of Doppler ultrasound will be discussed in this chapter. Direct heating effect with transvaginal transducer is avoided when the temperature of vaginal transducer is lower than $41^{\circ} \mathrm{C}$.

\section{Thermal Index}

One is $1^{\circ} \mathrm{C}$ power, i.e., the ultrasound power to rise the temperature of exposed tissue for $1^{\circ} \mathrm{C}$, because the lowest temperature rise and duration to develop animal anomaly was $1^{\circ} \mathrm{C}$ for 1,000 mins. ${ }^{4}$ The temperature rise was $1^{\circ} \mathrm{C}$ (absolutely $38^{\circ} \mathrm{C}$ ) and its duration was 1,000 mins in the thermal index (TI) $1,^{4}$ and ultrasound is safe if the TI is

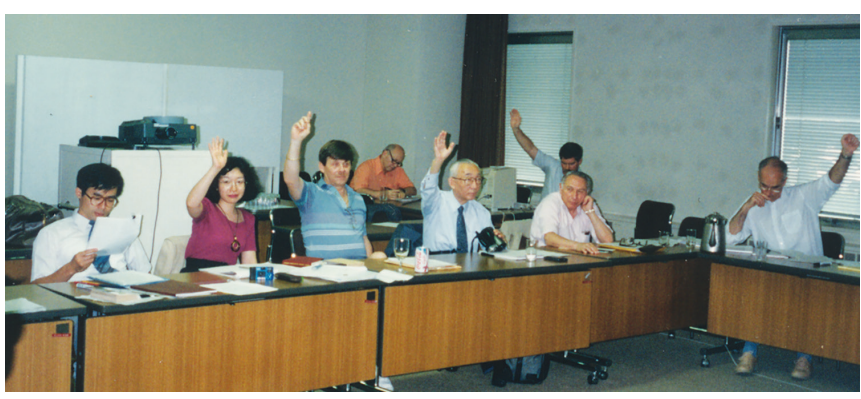

Fig. 1: The WFUMB committee symposium on diagnostic ultrasound safety held in Utsunomiya, Japan, 1994 
less than one. The TI is two if temperature rise is $2^{\circ} \mathrm{C}$, $\mathrm{TI}$ is three if the rise is $3^{\circ} \mathrm{C}$, then TI reaches six when the rise is $6^{\circ} \mathrm{C}$, and the duration is $1 \mathrm{~min}$ to develop anomaly. ${ }^{4}$ Thus, the lowest temperature rise is $1^{\circ} \mathrm{C}$ and $\mathrm{TI}=1$, where diagnostic ultrasound TI should be lower than one.

Soft tissue TI (TIs) is lower than bone TI (TIb) and transcranial TI (TIC). The TIb is used in the safety of ultrasound, where the TI is less than one, and the mechanical effect of ultrasound is expressed by mechanical index (MI), which is rarefactional pressure [MegaPascal (Pr)] divided by the square root of ultrasound frequency $(\mathrm{MHz})$. Obstetric diagnostic devices are set at ultrasonic intensities lower than 1.0 TI and lower than 1.0 MI.

The output intensity of simple B-mode equipment was regulated below the spatial peak temporal average (SPTA) intensity of $10 \mathrm{~mW} / \mathrm{cm}^{2}$ by the Japan Industrial Standard in 1980, where the intensity level was $1 / 24$ of the nonhazardous threshold of ultrasound, which was SPTA $240 \mathrm{~mW} / \mathrm{cm}^{2}$. These were the results of our experimental studies. ${ }^{5}$ Ultrasound Doppler flow velocity measurements, color, and power Doppler mappings are set at the level lower than $1.0 \mathrm{TI}$ and $1.0 \mathrm{MI}$, at present.

Recently, two studies ${ }^{6,7}$ reported the hazardous ultrasound effects; however, the results should be carefully analyzed because the ultrasound intensity was definitely lower than the level that produces a hazardous effect, but the results could have been obtained by the heating of the attached ultrasound probe. Due to transient increase of hepatic apoptosis of animal fetus after Doppler ultrasound exposure, ${ }^{8}$ the ISUOG regulated the use of Doppler ultrasound in early pregnancy. ${ }^{9}$ The report ${ }^{8}$ will be discussed in this article.

\section{Thermal Safety and Thermal Index}

Thermal index and mechanical index are basic indices to estimate the safety of diagnostic ultrasound, widely utilized in the world. Among them, the TI is determined by the temperature rise caused by diagnostic ultrasound absorption. Comparing the effect to the biological heating experiment of fetus and embryo of experimental animals, i.e., the National Council on Radiation Protection and Measurements (NCRP $)^{4}$ reported the results of direct heating of animal fetus and embryo to develop anomaly, that was the teratogenicity of heating, where the teratogenicity was shown after a temperature rise for 1 to $6^{\circ} \mathrm{C}$ above $37^{\circ} \mathrm{C}$ (absolutely $38-43^{\circ} \mathrm{C}$ ) for 1,000 to 1 minutes. High temperature and short heating $\left(43^{\circ} \mathrm{C} 1 \mathrm{~min}\right)$ to low temperature long exposure $\left(38^{\circ} \mathrm{C} 1,000\right.$ mins $)$ developed head and neck anomalies.

Therefore, researchers recognized the lowest temperature rise $\left(1^{\circ} \mathrm{C}\right)$ as the threshold of safe ultrasound exposure, i.e., the ultrasound intensity to rise $1^{\circ} \mathrm{C}$ at the imaging tissue was determined: One TI, where the TI lower than one was the safe intensity. One or higher TI should be displayed on the image monitor, and the device user should reduce TI to the level lower than one. ${ }^{3}$ The TI set at soft tissue is the soft tissue TI (TIs) and higher TI set at bone is the bone TI (TIb). TIb is used in the safety setting. The TI of obstetrical setting is $\mathrm{TI}<1$.

\section{Peculiar Thermal Problem in Transvaginal Scan}

The problem is caused by the direct attachment of ultrasound transducer to vaginal mucosa. The heating effect of transducer on the vagina and close pelvic organs was of concern in the transvaginal scan ultrasound.

The user of transvaginal scan ultrasound should be careful about the direct heating of the attached tissue due to high surface temperature of the transducer, which directly attaches to the vaginal wall, and the pelvic organs are closer than in the abdominal scan. Therefore, the transvaginal transducer temperature is regulated to be lower than $41^{\circ} \mathrm{C}$ because of possible hazards to the attached sensitive tissue by the heated transducer. The user of every intracavitary scan should also be careful about the transducer temperature.

\section{Other Thermal Issues}

As animal fetal skull or the brain surface was heated to the level of more than $4^{\circ} \mathrm{C}$ by the exposure to intense ultrasound, ${ }^{6}$ thermal damage of the brain could not be completely denied, and the use of maximum intensity Doppler ultrasound is inadvisable in a flow study even in late pregnancy.

Caution should be paid to the tissue exposed to intense ultrasound in febrile patients, ${ }^{3}$ where the basic temperature is higher than $37^{\circ} \mathrm{C}$. For example, if TI is two at $38^{\circ} \mathrm{C}$ febrile patient, the temperature rise above physiological condition is the same as TI 3 in a nonfebrile case, and therefore, ultrasound exposure will almost be not allowed.

\section{Nonthermal Safety with Mechanical Index}

Ultrasound bioeffect, other than thermal effect, was called mechanical effect, and it is expressed by the grade to develop cavitation, namely an ultrasound pulse was measured with negative pressure of pulse (Pr) (Graph 1), where the

$$
\mathrm{MI}=\operatorname{Pr} \text { (MegaPascal)/ Vultrasound frequency }(\mathrm{MHz})
$$

Diagnostic ultrasound is safe, and nonthermal effect of ultrasound is safe, if MI is lower than one. Therefore, either $\mathrm{TI}$ and $\mathrm{MI}<1$ in an obstetrical setting.

The TI, MI, and exposure duration are documented in the patient's record during every clinical study. The TI and MI are listed in the "Method" of the scientific report of ultrasound exposure. 


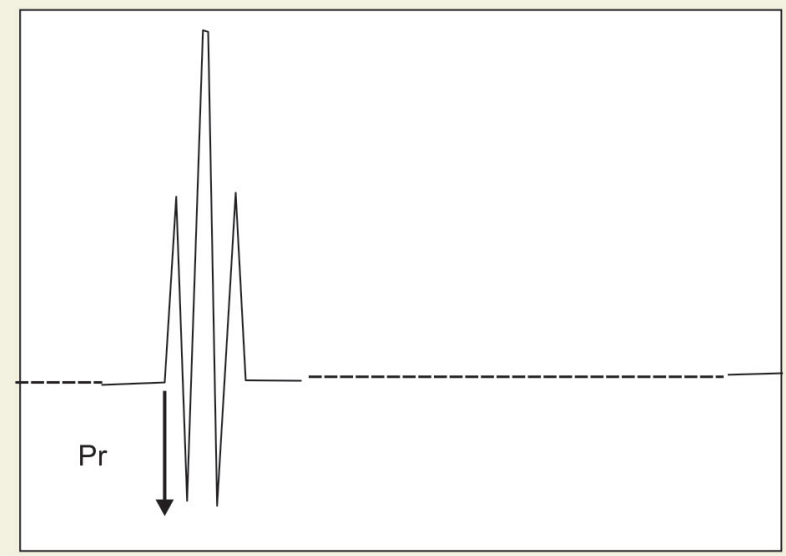

Graph 1: Rarefactional pressure (Pr)

\section{Safety of Doppler Ultrasound in Obstetrics}

The Doppler ultrasound intensity tended to be high in the general ultrasound study; therefore, its use to measure fetal blood flow velocity was a concern; however, recent obstetric Doppler ultrasound intensities are lower than the level of one TI.

Particularly, 0.1 to 0.5 TI Doppler ultrasound was termed as satisfactory in the obstetric Doppler study. Therefore, early pregnancy ductus venosus blood flow wave will be studied with 0.1 TI Doppler ultrasound. ${ }^{10}$ The TI measuring device provided by ISUOG will make it easy to study low TI.

\section{As Low As Reasonably Achievable}

As Low As Reasonably Achievable (ALARA) is a principle to reduce ultrasound intensity to achieve ultrasound safety, i.e., ultrasound intensity is reduced as low as possible if the result is favorable, e.g., Doppler intensity is reduced to $0.1 \mathrm{TI},{ }^{9}$ and reasonable result is achieved.

\section{Threshold Ultrasound Intensity Determined by JTC-3 Cultured Cell Growth}

Maeda et $\mathrm{al}^{5}$ determined the threshold of ultrasound bioeffect in continuous wave (CW) and pulse wave (PW) ultrasound, by the exposure to amniotic origin JTC-3 cultured cell growth curve in a Japanese study group granted by the Ministry of Health and Welfare.

The JTC-3 cultured cells, which was of fetal amniotic cell origin, were suspended in a culture medium held in an ultrasound transparent container and exposed to ultrasound, where the cell container was rotated for $2.5 \mathrm{rpm}$, and the growth ratio of cultured cells was compared to the noexposure control, 2, 4, and 7 days after the exposure, using the experimental ultrasound exposure system of the study group, where the cells were insulated from the heated ultrasound probe by inserting $37^{\circ} \mathrm{C}$ stabilized water between the probe and the cell container (Graph 2). Ultrasound intensity was informed by the manufacturer and confirmed by a steel ball moving method in the necessary situation. ${ }^{5}$

\section{Exposure of Cultured Cells to CW Ultrasound}

The JTC-3 cultured cells suspended in the culture medium in the tube rotating at $2.5 \mathrm{rpm}$ was exposed to CW ultrasound, where the heat of ultrasound probe was insulated by inserting $37^{\circ} \mathrm{C}$ stabilized water between the cell container and ultrasound probe.

The cell growth curve was suppressed by the exposure to $2 \mathrm{MHz} 2.6 \mathrm{~W} / \mathrm{cm}^{2} \mathrm{CW}$ ultrasound for $60 \mathrm{~min}$, while $0.8 \mathrm{~W} / \mathrm{cm}^{2}$ intensity $\mathrm{CW}$ showed no suppression, and it was suppressed by $1.7 \mathrm{~W} / \mathrm{cm}^{2}$ ultrasound. Therefore, the threshold power of CW ultrasound intensity to suppress cultured cell was $1 \mathrm{~W} / \mathrm{cm}^{2}$.

\section{Exposure of Cultured Cells to PW Ultrasound}

Cultured JTC-3 cells were exposed to PW ultrasound, of which the intensity was $240 \mathrm{~mW} / \mathrm{cm}^{2}$ suspended in

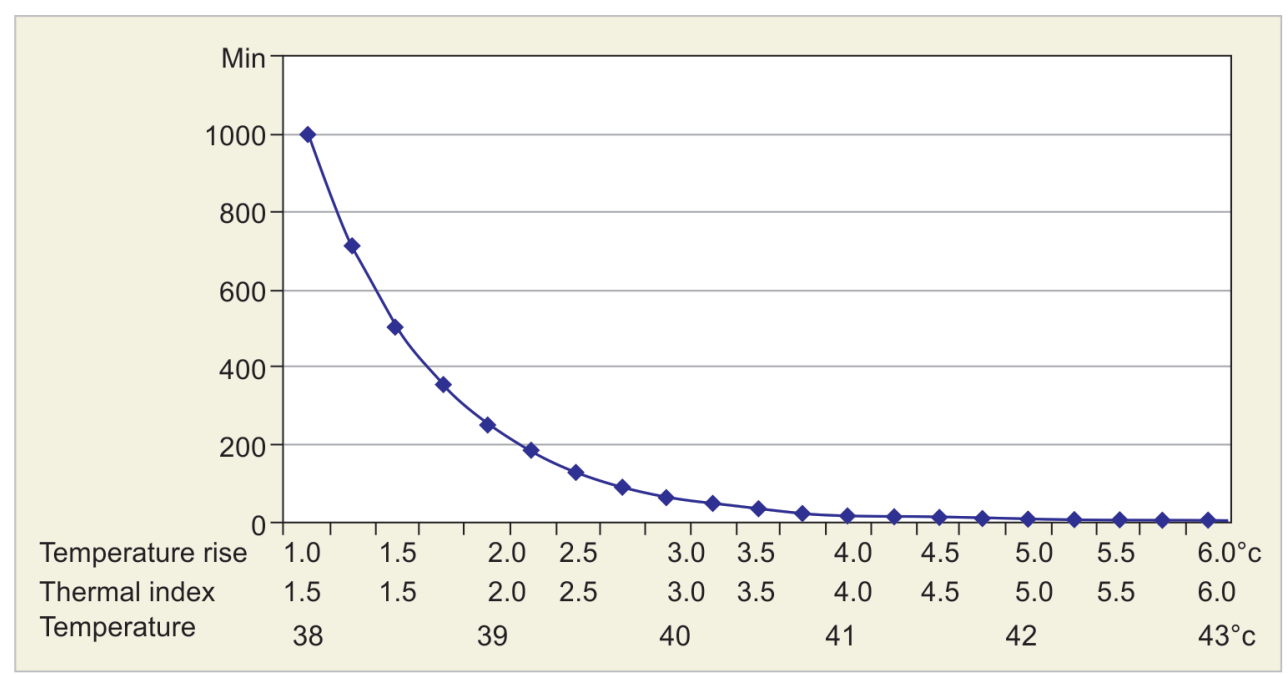

Graph 2: Thermal index and nonhazardous exposure time (mins) 


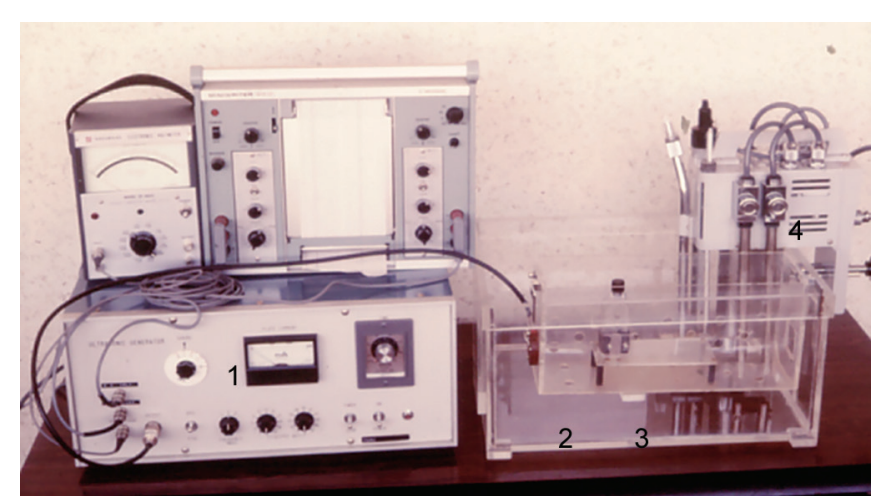

Fig. 2: Experimental ultrasound exposure system in Japanese study group on ultrasound bioeffect: (1) Ultrasound generator, (2) ultrasound probe, (3) exposure subject insulated from the heat of ultrasound probe, (4) water temperature stabilizer

cultured medium in a rotating tube for $2.5 \mathrm{rpm}$, where the heat of the ultrasound probe was insulated by inserting $37^{\circ} \mathrm{C}$ stabilized water between the cell container and ultrasound probe. ${ }^{5}$

The $2 \mathrm{MHz}$ ultrasound pulse duration was 3 or $10 \mu \mathrm{S}$, repetition frequency was 250 to $1,000 \mathrm{~Hz}$, and exposure time was $30 \mathrm{~min}$. Relative growth rate was suppressed by the exposure to PW ultrasound of which intensity was higher than $240 \mathrm{~mW} / \mathrm{cm}^{2}$, and there was no suppression comparing no-exposure control group at SPTA 240 or less $\mathrm{mW} / \mathrm{cm}^{2}$ at 2 to 7 days after the exposure. Therefore, no bioeffect was found if the intensity of PW ultrasound is 240 or lower $\mathrm{mW} / \mathrm{cm}^{2}$.

In summary, there was no ultrasound bioeffect, if CW ultrasound intensity was less than $1 \mathrm{~W} / \mathrm{cm}^{2}$, and PW ultrasound intensity was less than SPTA 240 $\mathrm{mW} / \mathrm{cm}^{2}{ }^{5}$

The results were authorized by the Japanese Society of Medical Ultrasonics in 1981 (Fig. 2).

\section{RECENT REPORTS}

Recently, three studies have discussed the effects of ultrasound exposure to pregnant mice and rats.

1. Prenatal exposure to ultrasound waves impacts neuronal migration in mice. ${ }^{6}$

A commercial real-time imaging ultrasound probe was attached to the abdomen of pregnant mice detecting fetal animal images for various durations, then studied the neuronal cell migrations of neonatal animals, and there were adverse effects including the delay of neuronal cell migration after 30 or more min exposure to the diagnostic ultrasound.

The ultrasound intensity of abdominal scan diagnostic ultrasound would be lower than $10 \mathrm{~mW} / \mathrm{cm}^{2}$, and the intensity would not develop hazardous bioeffect, because the ultrasound intensity was lower than the threshold of ultrasound bioeffect, which was $240 \mathrm{~mW} / \mathrm{cm}^{2}$ in the exposure to fetal origin-cultured cells. ${ }^{5}$ Therefore, there must have been any artifact that produced the change of fetal neuronal cells in the experiment. ${ }^{3}$ Since head and neck anomalies developed by the direct heating of embryo and fetus of animals, ${ }^{4}$ and the heat of $40 \mathrm{~mW}$ ultrasound probe developed fetal mice head anomaly after 6 hours' direct contact with pregnant mice, ${ }^{11,12}$ the central nervous system seemed sensitive to heating. As direct heating of fetal animals developed head and neck anomalies, ${ }^{4}$ abnormal fetal brain may suggest the heating of the fetus.

Was there any source to heat fetal mice? Yes, it was the heat of ultrasound probe: Namely, the probe produced ultrasound and received reflected ultrasound, and at the same time, it produced the heat by the passing-through electric current, namely, the ultrasound probe would be an electric heater, e.g., transvaginal scan probe temperature was regulated to be lower than $41^{\circ} \mathrm{C}$, therefore, the other probe, e.g., abdominal scanner, must be heated to $41^{\circ} \mathrm{C}$ or more. Therefore, fetal animals must have been heated by the directly attached abdominal scan probe to pregnant animals for 30 or longer minutes. However, body capacity of human pregnant women is 500 times larger than mouse. Therefore, the effective heating of pregnant women would be impossible. Thus, the present reports ${ }^{6,7}$ are not applicable to the ultrasound studies in human pregnancy.

It will be necessary to cut off the probe heating as has done in our study group ${ }^{5}$ to test the exposure to pure ultrasound without artifact caused by probe heating.

Actually, fetal mice head anomaly developed by attaching ultrasound probe directly to pregnant mice, ${ }^{11}$ and no fetal anomaly developed after the exposure to ultrasound where the probe was separated from pregnant mice by inserting $37^{\circ} \mathrm{C}$ water between the ultrasound probe and pregnant mice in the Japanese group study. ${ }^{12}$ 2. Prenatal exposure to ultrasound affects learning and memory in young rats. ${ }^{7}$ Ultrasound MedBiol 2015 Mar;41(3).

Pregnant rats were exposed to the ultrasound, which was $3.5 \mathrm{MHz}$, SPTA $106 \mathrm{~mW} / \mathrm{cm}^{2}$, MI 1.4, TIB 1.0, for $20 \mathrm{~min}$ three times; then, learning and memory functions and hippocampus were found damaged in 2 months after birth, while $7.6 \mathrm{~mW} / \mathrm{cm}^{2}$, MI 0.1, and $\mathrm{Tlb} 0.1,4$ min exposure developed no damage, but an improved function.

Ultrasound could not be the cause of results, because ultrasound intensity was $106 \mathrm{~mW} / \mathrm{cm}^{2}$, which was lower than the $240 \mathrm{~mW} / \mathrm{cm}^{2}$ of the ultrasound bioeffect threshold. ${ }^{5}$ The ultrasound intensity was 10 or more times higher than in the report of Ang et $\mathrm{al}^{6}{ }^{6}$ but the hazard was the damage of the central nervous system. This was similarl to the result of Ang et al; 6 therefore, the hazard might have been caused by an artifact, maybe by the heating of the attached probe, which might be $41^{\circ} \mathrm{C}$ or more. In addition, TI was 1.0, where temperature rise caused by the absorption of ultrasound was $1^{\circ} \mathrm{C}$; therefore, fetal 
temperature would be $41+1=42^{\circ} \mathrm{C}$, which suggested the hazard of central nervous system by repeated $20 \mathrm{~min}$ exposure to heat. ${ }^{4}$ The hippocampal change would be caused by repeated exposures to $42^{\circ} \mathrm{C}$ heat. The heating does not develop in human pregnant women; therefore, it will inapplicable in human pregnancy diagnosis. In addition, TI is less than 1.0 in obstetrical setting, namely, heating caused by ultrasound absorption will be ineffective in clinical cases.

3. Ultrasound bioeffects in rats: Quantification of cellular damage in the fetal liver after pulsed Doppler imaging. 8

Ductus venosus Doppler blood flow was studied in fetal rat with diagnostic ultrasound devices including $13 \mathrm{MHz}$ two-dimensional ultrasound probe and 5.8 $\mathrm{MHz}, 140 \mathrm{~mW} / \mathrm{cm}^{2}$, frame rate 26.5. The TI and MI $<1.0$ pulsed Doppler. Exposure time was 20 or more seconds. Then fetal liver apoptosis index was transitorily increased at 7 days after exposure to ultrasound. No neonatal or infantile abnormality was reported after the exposure. The apoptosis of liver is divided into extrinsic apoptosis and physiologic intrinsic apoptosis, ${ }^{13}$ and the latter is enhanced by high-frequency vibrations. ${ }^{13}$ As the frequency of ultrasound devices used in the study was as high as $13 \mathrm{MHz}$ and $5.8 \mathrm{MHz}$; therefore, fetal liver apoptosis would have been possible to be an enhanced physiologic intrinsic one. As no neonatal abnormality is reported, this idea cannot be completely denied.

As Doppler ultrasound intensity was $140 \mathrm{~mW} / \mathrm{cm}^{2}$, which was lower than $240 \mathrm{~mW} / \mathrm{cm}^{2}$, below which no ultrasound bioeffect was found, ${ }^{5}$ the apoptosis index can be intrinsic and physiologic one enhanced by high frequency of ultrasound. Probe heating could not be an artifact, because of short exposure time.

\section{Discussion on Recent Three Reports}

\section{Animal Fetal and Infantile Damages in Ang et $a^{6}$ and Li et al Reports}

Thermal effect of ultrasound is caused by the absorption of ultrasound to biological tissue, and it may damage developing tissue of embryo and fetus, associating the teratogenicity in severe direct heating, where fetal abnormality was produced in fetal head and neck. ${ }^{4}$ As the fetal abnormality developed in fetal head was cranial meningocele, it was caused by the heated ultrasound probe. ${ }^{11}$ Heavy fetal heating developed the anomalies in the head and neck, ${ }^{4}$ and moderate-to-mild heating may develop the damage of the fetal central nervous function, which was confirmed in the two reports. ${ }^{6,7}$ The fetal heating does not occur in pregnant women because of definitely larger body volume than small animals. Therefore, the results of Ang and Li are not the cases of ultrasound diagnosis of human pregnancy.

\section{Fetal Liver Apoptosis of Pellicer et a ${ }^{\beta}$}

Liver apoptosis was classified into extrinsic and intrinsic ones, where extrinsic apoptosis was caused by external hazards, e.g., inflammation and immunization, which may develop fetal or neonatal damages, but neither neonatal nor infantile hazard is reported in the study. Therefore, hazardous extrinsic apoptosis will be difficult to be classified. Ultrasound intensity is lower than threshold; ${ }^{5}$ therefore, the ultrasound would not be effective in this report. The intrinsic apoptosis is a physiologic benign one, which was increased by the presence of high-frequency vibration. ${ }^{13}$ As such high-frequency ultrasound as $13 \mathrm{MHz}$ B-mode and 5.8 MHz Doppler probes were utilized in the report; physiologic apoptosis can be enhanced by the radiation of high-frequency ultrasound. As the increase of apoptosis was transitory, and no abnormality was reported in neonatal and infantile animals, the apoptosis in Pellicer et $\mathrm{al}^{8}$ report might be intrinsic and physiologic. ${ }^{13}$ The ISUOG allowed restricted use of Doppler ultrasound in early pregnancy to confirm fetal trisomy, ${ }^{9}$ maybe due to the possibility of physiologic nature of apoptosis, while no routine use of Doppler ultrasound was prohibited in 11 to $13+6$ weeks of pregnancy, maybe with the purpose for prudent use of Doppler ultrasound. As 0.1 TI Doppler ultrasound, may be around $20 \mathrm{~mW} / \mathrm{cm}^{2}$, did not compromise Doppler measurement, ${ }^{10}$ low-intensity Doppler may be a prudent use of Doppler ultrasound in early pregnancy.

\section{Conclusion of Recent Three Reports}

The heating of ultrasound probe would not be hazardous to human pregnancy, while the small pregnant animal was influenced by the longer attachment of probe than $30 \mathrm{~min}$ in case of small pregnant animals, while ultrasound exposure produces no bioeffect, if the output intensity is lower than $240 \mathrm{~mW} / \mathrm{cm}^{2}$, or TI and MI are definitely lower than 1.0. The principle was confirmed again in the studies on recent three reports.

\section{D Ultrasound Safety}

The 3D ultrasound image is a computerized surface rendering, where multiple real-time B-mode images are scanned with definite intervals in a few seconds, and the images are filed in the computer memory to receive computer rendering. Therefore, the $3 \mathrm{D}$ ultrasound is a repeated B-mode image acquisition, namely, it is a kind of low-intensity B-mode ultrasound image, if it is a simple 3D ultrasound. Each B-mode ultrasound is less than $10 \mathrm{~mW} / \mathrm{cm}^{2}$, i.e., TI and MI are less than 1 . However, the safety changes when Doppler ultrasound is associated to $3 \mathrm{D}$ ultrasound, where the safety is determined by the intensity of Doppler ultrasound. 


\section{D Ultrasound Safety}

The $4 \mathrm{D}$ ultrasound is continuously changing 10 to 20 flames of 3D ultrasound images with quick rendering. Therefore, principally, 4D ultrasound is repeated B-mode imaging ultrasound; therefore, it is as safe as real-time B-mode ultrasound images. The TI and MI are less than one. The safety should be determined by associated Doppler ultrasound.

\section{The Safety of Doppler Ultrasound}

Principally, the TI and MI of Doppler flow studies should be less than one in obstetrics, though Doppler TI and MI were high in old times.

Particularly, recently, 0.1 to 0.5 TI was utilized successfully without any problem in Doppler flow wave studies. ${ }^{10}$ It will be an actual example of the ALARA principle. 0.1 Doppler ultrasound will be recommended to the ductus venosus Doppler flow study in $11-13+6$ weeks of gestation. ${ }^{8,9}$

\section{REFERENCES}

1. Barnett SB, Kossoff G. WFUMB symposium on safety and standarsation in medical ultrasound. Issues and recommendations regarding thermal mechanisms for biological effects of ultrasound, Hornbick, 1991. Ultrasound Med Biol 1992;18(9):731-814.

2. Barnett SB, Rott HD, Ter Haar GR, Ziskin MC, Maeda K. The sensitivity of biological tissue to ultrasound. Ultrasound Med Bol 1997 Feb;23(6):805-812.

3. American Institute of Ultrasound in Medicine/National Electrical Manufacturers Association. Standard for real time display of thermal and mechanical acoustic output indices on diagnostic ultrasound equipment. Laurel, MA: AIUM/ NEMA; 1992.
4. National Council on Radiation Protection and Measurements (NCRP). Report No.113, Exposure criteria for medical diagnostic ultrasound: I. Criteria based on thermal mechanisms, NCRP; 1992 June. p. 278.

5. Maeda K, Murao F, Yoshiga T, Yamauchi C, Tsuzaki T. Experimental Studies on the suppression of cultured cell growth curves after irradiation with $\mathrm{CW}$ and pulsed ultrasound. IEEE Trans Ferroelectr Freq Control 1986 Mar;33(2): 186-193.

6. Ang ES, Gluncic V, Duque A, Schafer ME, Rakic P. Prenatal exposure to ultrasound waves impacts neuronal migration in mice. Proc Natl Acad Sci USA 2006 Aug;103(34): 12903-12910.

7. Li P, Wang PJ, Zang W. Prenatal exposure to ultrasound affects learning and memory in young rats. Ultrasound Med Biol 2015 Mar;41(3):644-653.

8. Pellicer B, Herraiz S, Taboas E, Felipo V, Simon C, Pellicer A. Ultrasound bioeffects in rats: quantification of cellular damage in the fetal liver after pulsed Doppler imaging. Ultrasound Obstet Gynecol 2011 Jun;37(6):643-648.

9. Salvesen K, Lees C, Abramowicz J, Brezinka C, Ter Haar G, Maršál K, Board of International Society of Ultrasound in Obstetrics and Gynecology (ISUOG). ISUOG statement on the safe use of Doppler in the 11 to $13+6$ week fetal ultrasound examination. Ultrasound Obstet Gynecol 2011 Jun;37(6):625-628.

10. Sande RK, Matre K, Elde GE, Kiserud T. Ultrasound safety in early pregnancy: reduced energy setting does not compromise obstetric Doppler measurements. Ultrasound Obstet Gynecol 2012 Apr;39(4):438-443.

11. Shimizu T, Fukushima T, Shoji R. Teratogenicity and ultrasound exposure. Obstet Gynecol (Japan) 1970;37:1339-1343.

12. Shimizu T, Tanaka K. Basic studies on the bioeffect of pulse wave ultrasound. Special issue, studies on the safety of pulse wave ultrasound on the fetus. Ultrasound Med 1981;8: 289-292.

13. Gucciardi, ME, Malhi H, Mott JL, Gores GJ. Apoptosis and necrosis in the liver. Compr Physiol 2013 Apr;3(2):977-1010. 